\title{
Assessment of periapical status: A comparative study using film-based periapical radiographs and digital panoramic images
}

\author{
José V. Ríos-Santos ${ }^{1}$, Cristina Ridao-Sacie ${ }^{1}$, Pedro Bullón ${ }^{1}$, Ana Fernández-Palacín ${ }^{2}$, Juan J. Segura-Egea ${ }^{1}$ \\ ${ }^{1}$ Department of Stomatology, School of Dentistry, University of Seville \\ ${ }^{2}$ Department of Socio-Health Sciences, School of Dentistry, University of Seville
}

Correspondence:

Department of Stomatology,

School of Dentistry, University of Seville

C/Avicena s/n.

41009-Seville, Spain,

segurajj@us.es.

\author{
Ríos-Santos JV, Ridao-Sacie C, Bullón P, Fernández-Palacín A, Segura- \\ Egea JJ. Assessment of periapical status: A comparative study using film- \\ based periapical radiographs and digital panoramic images. Med Oral \\ Patol Oral Cir Bucal. 2010 Nov 1;15 (6):e952-6. \\ http://www.medicinaoral.com/medoralfree01/v15i6/medoralv15i6p952.pdf

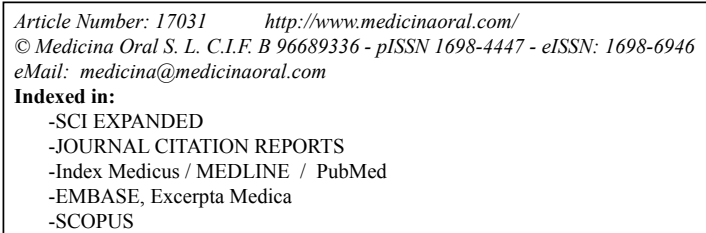

\begin{abstract}
Aim: To compare the use of film-based periapical radiographs and digital panoramic images displayed on monitor and glossy paper in the assessment of the periapical status of the teeth. Methodology: A total of 86 subjects were examined. All participants underwent a full-mouth radiographic survey (14 periapical radiographs) and a digital panoramic radiography. The periapical status of all appraised teeth was assessed. Results: Periapical radiographs allowed the assessment of the periapical status of a significantly higher percentage of teeth (87.4\%) Digital radiography had a significantly reduced potential to allow assessment of the periapical status $(p<0.01)$. Only $58.0 \%$ and $34.3 \%$ of teeth could be appraised using digital panoramic images displayed on monitor and glossy paper respectively $(\mathrm{p}<0.01)$. The total percentage of teeth with periapical pathosis was four-fold higher when assessed with digital panoramic images displayed on glossy paper compared with periapical radiographs $(p<0.01)$. Conclusions: Periapical radiographs allowed the assessment of a significantly higher percentage of teeth when comparing to digital radiography, which had a significantly lower potency in the assessment of periapical status of the teeth. Digital panoramic images displayed on a monitor resulted in a significantly higher percentage of appraised teeth compared to digital images displayed on glossy paper. Apical periodontitis was scored more often on paper than on screen, and more often on screen than in periapical radiographs.
\end{abstract}

Key words: Apical periodontitis, oral radiology, orthopantomography, digital radiology. 


\section{Introduction}

Radiological examination is a main tool for a thorough exploration in dentistry $(1,2)$ Moreover, in endodontics, the radiological assessment of the periapical status, determining the incidence and prevalence of apical periodontitis, is important because it may help to define treatment needs and to relate treatment outcome to various technical and clinical factors of endodontic therapy (3). In the evaluation of the apical periodontium, bone density changes and the pattern and structure of the trabeculae around the apex of the tooth are the most consistent feature of the presence, progression or resolution of periapical inflammation present in radiographs (4). However, radiography did not provide detection of periapical lesion in its initial stages. To be detected by the human visual system an approximate $30 \%$ change in bone mineral content is necessary (3). Both periapical radiography and panoramic radiography have been used to assess the periapical status both in experimental (5) and epidemiological studies (6-11)

Several studies have evaluated the diagnostic accuracy of digital images printed on hard copy media compared with that of the monitor-displayed image (12-14).

The purpose of this study was to compare the use of film-based periapical radiographs and digital panoramic images displayed on monitor and glossy paper in the assessment of the periapical status of the teeth, comparing the number of assessable teeth in panoramic versus intraoral radiographs.

\section{Materials and Methods}

The sample consisted of 86 subjects, 38 males (44\%) and 48 females (56\%), aged $30-79$ years, presenting as new patients seeking routine dental care (not emergency care) at the University of Seville, Faculty of Dentistry, between the years 2007 and 2008. The criteria for inclusion in the study were as follows: 1) patients should be attending for the first time; 2) patients must be over 18 -years-old; 3 ) patients having less than 10 remaining teeth were excluded; 4) patients having a community periodontal index scoring $>3$ in at less two posterior sextants, who needed a full mouth radiographic survey; 5) patients requiring a panoramic radiograph because of third molar surgery, cysts or tumours. The Ethics Committee of the Dental Faculty approved the study and all the patients gave written informed consent.

All participants underwent a full-mouth radiographic survey consisting of 14 periapical radiographs and a panoramic radiography. The panoramic radiographs and the periapical radiographs were taken as described previously (15)

From the full-mouth radiographic survey, as well as from the panoramic radiography, all teeth were recorded according to the FDI nomenclature and the periapical status on all appraised teeth was assessed as de- scribed previously by Chugal et al. (16). The method of viewing the periapical radiographs was standardized as described previously (17). The interpretation of radiographs was performed by two examiners with extensive clinical experience in endodontics. The intra-examiner reliability was evaluated by the repeat scoring of $30 \mathrm{pa}-$ tients two months after the first examination. The interexaminer reliability was evaluated comparing the scoring of these 30 patients. The reliability was determined by calculating Kappa (intra-examiner $=0.81$ and 0.86 ) and inter-examiner (0.78).

\section{- Statistical analysis}

The variables tested were "average number of teeth per patient", "percentage of assessable teeth", "teeth that could not be appraised" and "percentage of teeth with apical periodontitis". Raw data were entered into Access ${ }^{\circledR}$ (Microsoft Corporation, Redmond, WA, USA). The Chi-squared test (with the Yates' correction if indicated) and the Cochran test were used to determine the significance of differences using the SPSS program 12.0 for windows. The level for statistical significance was set at $\mathrm{p}<0.05$.

\section{Results}

Inter- and intra-observer Kappa values were above 0.75 , ensuring adequate reproducibility. The average number of teeth per patient was $24 \pm 4$ teeth. No significant differences between males and females were found for number of teeth.

The percentage of assessable teeth amongst the 2088 which were examined is showed on Table 1. Periapical radiographs allowed the assessment of a significantly $(\mathrm{p}<$ 0.0005 ) higher percentage of teeth, $83 \%$ in the upper jaw and $91 \%$ in the lower one. However, maxillary second molar teeth as well as both maxillary and mandibular third molar teeth were more difficult to evaluate using periapical radiographs $(\mathrm{p}<0.05)$, but digital panoramic images did not show a significantly higher percentage of appraised third molar teeth $(p>0.05)$. Digital panoramic images displayed on a monitor resulted in a higher percentage of appraised teeth compared to digital images displayed on glossy paper in all cases $(p<0.05)$.

Table 2 shows teeth, grouped by type, which could not be appraised in periapical or panoramic radiographs (NAT) and the percentage of appraised teeth with apical periodontitis (ATAP). Periapical radiographs allowed the assessment of the periapical status of $87.4 \%$ of teeth (12.6\% teeth could not be evaluated). On the contrary, digital radiography had a significantly lower potency in the assessment of periapical status $(\mathrm{p}<0.01)$. Only $58.0 \%$ and $34.3 \%$ of teeth could be appraised using digital panoramic images displayed on monitor and glossy paper, respectively $(\mathrm{p}<0.01)$. However, digital panoramic images displayed on monitor allowed the assessment of the periapical status of both maxillary and 
Table 1. Percentage of assessable teeth in periapical and digital panoramic radiographs. Ortho paper: panoramic radiograph printed in paper; Ortho screen: panoramic radiograph viewed in the screen.

\begin{tabular}{|c|c|c|c|c|c|c|c|c|c|}
\hline UPPER TEETH & $\mathbf{1}$ & $\mathbf{2}$ & $\mathbf{3}$ & $\mathbf{4}$ & $\mathbf{5}$ & $\mathbf{6}$ & $\mathbf{7}$ & $\mathbf{8}$ & $\mathbf{T O T A L}^{\text {** }}$ \\
\hline Periapical & 98 & 96 & 85 & 96 & 98 & 89 & 51 & 13 & 83 \\
\hline Ortho - Screen & 49 & 59 & 57 & 40 & 59 & 43 & 64 & 45 & 53 \\
\hline Ortho - Paper & 26 & 27 & 28 & 17 & 31 & 17 & 39 & 27 & 27 \\
\hline LOWER TEETH & $\mathbf{1}$ & $\mathbf{2}$ & $\mathbf{3}$ & $\mathbf{4}$ & $\mathbf{5}$ & $\mathbf{6}$ & $\mathbf{7} *$ & $\mathbf{8}$ & TOTAL \\
\hline Periapical & 99 & 95 & 90 & 96 & 97 & 99 & 85 & 52 & 91 \\
\hline Ortho - Screen & 38 & 42 & 46 & 67 & 83 & 94 & 91 & 52 & 62 \\
\hline Ortho - Paper & 13 & 24 & 30 & 39 & 59 & 74 & 71 & 45 & 41 \\
\hline
\end{tabular}

Cochran Test $\mathrm{p}<0.0005 ; \mathrm{p} \leq 0.05 ; * * \mathrm{p} \leq 0.01$

Table 2. Percentage of non-appraised teeth (NAT) and percentage of appraised teeth with apical periodontitis (ATAP) in periapical and digital panoramic radiographs. Maxillary teeth (top value), mandibular teeth (centre value) and total teeth (bottom value). Cochran test was used to calculate the $p$ value.

\begin{tabular}{|c|c|c|c|c|c|c|}
\hline & \multicolumn{2}{|c|}{$\begin{array}{c}\text { Periapical } \\
\text { Radiography }\end{array}$} & \multicolumn{2}{|c|}{$\begin{array}{c}\text { Panoramic } \\
\text { Radiography } \\
\text { (Screen) }\end{array}$} & \multicolumn{2}{|c|}{$\begin{array}{c}\text { Panoramic } \\
\text { Radiography (Paper) }\end{array}$} \\
\hline & $\%$ NAT & $\%$ ATAP & $\%$ NAT & $\%$ ATAP & $\%$ NAT & $\%$ ATAP \\
\hline \multirow{3}{*}{$\begin{array}{l}\text { Incisors and } \\
\text { canines }\end{array}$} & 6.3 & 2.3 & 45.3 & $4.0^{*}$ & 71.9 & $10.1+\dagger$ \\
\hline & 5.6 & 3.7 & 54.6 & 3.2 & 77.0 & $10.5 t \dagger$ \\
\hline & 6.0 & 3.0 & 52.1 & $3.6^{*}$ & 75.2 & $10.3+\dagger$ \\
\hline \multirow{3}{*}{ Bicuspids } & 2.8 & 5.5 & 51.8 & $11.4^{*}$ & 77.1 & $27.5+\dagger$ \\
\hline & 3.4 & 1.4 & 26.0 & $6.1^{* *}$ & 52.5 & $12.3 t$ \\
\hline & 3.1 & 3.6 & 37.3 & $7.8^{* *}$ & 62.8 & $16.9+t$ \\
\hline \multirow{3}{*}{ Molars } & 44.8 & 6.0 & 46.9\# & $13.6^{* *}$ & 72.0 & $17.9 \dagger$ \\
\hline & 19.6 & 7.2 & $15.8 \#$ & $21.9^{* *}$ & 35.0 & 19.3 \\
\hline & 32.8 & 6.7 & $32.3 \#$ & $18.1^{* *}$ & 54.4 & 18.8 \\
\hline \multirow{3}{*}{ All teeth } & 16.6 & 3.9 & 49.9 & $8.3^{* *}$ & 73.9 & $15.8 \dagger$ \\
\hline & 9.0 & 4.1 & 36.9 & $11.3^{* *}$ & 58.5 & 14.9 \\
\hline & 12.6 & 4.0 & 42.0 & $9.9^{* *}$ & 65.7 & $15.6 \dagger$ \\
\hline
\end{tabular}

$\# p>0.05$ periapical versus screen.

$* \mathrm{p}<0.05$ periapical vs screen; $* * \mathrm{p}<0.01$ periapical vs screen.

$\dagger \mathrm{p}<0.05$ screen vs paper; $\dagger \dagger \mathrm{p}<0.01$ screen vs paper. 
mandibular molar teeth as well as periapical radiographs $(p>0.05)$. Digital images displayed on glossy paper resulted in the lowest percentage of appraised teeth in all cases $(\mathrm{p}<0.05)$.

Respect the percentage of appraised teeth with apical periodontitis (ATAP), in all cases, digital panoramic images displayed on glossy paper had the higher percentage of teeth with apical periodontitis $(\mathrm{p}<0.05)$. Moreover, the total percentage of periapically diseased teeth was four-fold higher when assessed with digital panoramic images displayed on glossy paper $(15.6 \%)$ compared to periapical radiographs $(4.0 \%)(\mathrm{p}<0.01)$. Digital panoramic images displayed on the screen also had a two-fold higher total percentage of diseased teeth compared to periapical radiographs $(\mathrm{p}<0.01)$. Comparing the two digital panoramic images, the glossy paper images had a significantly higher percentage of diseased teeth than images displayed on the screen $(\mathrm{p}<$ 0.05 ). However, significant differences between the two digital images in molar teeth were not found.

\section{Discussion}

The results of this study showed that periapical radiographs allowed higher percentage of apices, with the exception of maxillary molars, that were better viewed in orthopantomograms. Ridao-Sacie et al. (15) reported similar results using the PAI scoring system described by Ørstavik et al. (17), although maxillary second and third molars were better viewed in digital panoramic images displayed on a monitor or on glossy paper.

Digital periapical radiographs and digital orthopantomography are both an excellent mean to document the succession of the treatment and the correct indication of some therapies (18). Previous studies have compared the diagnostic accuracy of digital images printed on hard copy media compared with that of the monitordisplayed image. Russell and Pitts (19) analyzed the sensitivity in the caries detection finding that for occlusal caries, overall the sensitivity and specificity of RVG videoprints are similar to those of bitewing radiography, and for approximal caries, the specificity of RVG videoprints was similar to that of bitewing radiography, but the sensitivity was slightly lower. Recently, Forner-Navarro et al. (20) have shown that RVG digital radiography was as effective as conventional radiography in diagnosing caries. Pecoraro et al. (12) studied the reproducibility in assessing alveolar bone height on direct digital and conventional radiographs concluding that alveolar bone measurements are reproducible on both digital and conventional radiographs. Li et al. (13) analyzed the accuracy and precision of measurements on marginal bone levels in differently processed digital radiographs and in film-based radiographs, concluding that digital radiographs have a favourable measurement accuracy compared with film radiographs when as- sessing marginal bone levels. Another study evaluated subjective image quality and obviousness of anatomical structures in thermal prints and monitor-displayed digital panoramic images (14), finding that both formats had acceptable diagnostic utility for the majority of the anatomic features evaluated.

The present results showed that percentage of non-appraised teeth in periapical radiographs was higher in the maxilla compared to the mandible. Among the causes that could justify this finding are two: 1) the difficulty of using correctly paralleling technique in the maxilla when the patient has a low palate, and 2) that the anterior wall of the maxillary sinus extends over the premolar teeth.

In the present study it is not surprising that lower anterior teeth are seen less well in the panoramic radiograph. However, to find almost as many in the upper anterior region is surprising. It must be taken in mind that this study used digital panoramic radiographs displayed on monitor or glossy paper, not film-based panoramic radiographs. Upper anterior teeth are well seen in film-based panoramic radiographs, but the present results demonstrate that when digital panoramic image is displayed on monitor, upper anterior teeth are seen less well, and even worse when printed on glossy paper. We think the reasons could be two: 1) In panoramic radiograph, if the patient's chin is tilted up too, the radiopaque shadow of the hard palate overlaps on the roots of the upper anterior teeth. 2) A common technical failure during panoramic radiograph is the lack of contact of the tongue with the palate. Then, the air resulting in the mouth is shown in the radiograph as a radiolucency or "burned image" on the upper anterior teeth. In both cases, the transparency of film-based panoramic radiograph allows to assess the periapical status of the upper anterior teeth, but in digital panoramic image displayed on monitor or, furthermore, on glossy paper the opacity of the image can prevent the assessment of the periapical status.

The results of the present study show that the total percentage of periapically diseased teeth ranged from $4 \%$ to $15.6 \%$. Ridao-Sacie et al. (15) using the PAI scoring system (17), also reported a significantly higher percentage of periapically diseased teeth with digital panoramic images displayed on glossy paper (14.7\%) compared to periapical radiographs (3.1\%). These authors scored apical periodontitis more often on paper than on screen, and more often on screen than in periapical radiographs.

The surprisingly high number of periapical lesions in the panoramic images reported in the present study, particularly on the copies printed on paper, could be explained as follows. X-ray images obtained with digital dental radiographic systems are commonly viewed on a cathode ray tube (CRT) display. On the contrary, in 
the present study the images were viewed on a regular 17-inch CRT monitor instead of on a medical diagnostic grey-scale monitor.

An accepted full mouth survey have to show all teeth/ roots, but to show does not imply it could be assessed the periapical status of the teeth/roots. On the contrary, the findings of the present study show that an accepted full mouth survey using periapical radiographs only allows the assessment of the periapical status of $87.4 \%$ of teeth, including third molars. Moreover, these results demonstrated that an accepted full mouth survey using digital panoramic images displayed on monitor only allows the assessment of the periapical status of $58.0 \%$ of the teeth; and an accepted full mouth survey using digital panoramic images on glossy paper only allows the assessment of the periapical status of $34.3 \%$ of teeth.

\section{Conclusions}

Film-based periapical radiographs allowed the assessment of the periapical status of a significantly higher percentage of teeth. Digital radiography had a significantly lower potency in the assessment of periapical status. In addition, digital panoramic images displayed on a monitor resulted in a significantly higher percentage of appraised teeth compared to digital images displayed on glossy paper in all cases. Apical periodontitis was scored more often on paper than on screen, and more often on screen than in periapical radiographs.

\section{References}

1. Jiménez-Rubio A, Segura JJ, Feito JJ. A case of combined dental development abnormalities: importance of a thorough examination. Endod Dent Traumatol. 1998;14:99-102.

2. Segura JJ, Jiménez-Rubio A, Cabrera R. Intracoronal radiolucency in an incompletely erupted permanent molar with a diagnosis of pericoronitis: importance of radiographic examination. Oral Surg Oral Med Oral Pathol Oral Radiol Endod. 1998;85:461.

3. Orstavik D. Radiographic evaluation of apical periodontitis and endodontic treatment results: a computer approach. Int Dent J. 1991;41:89-98.

4. Delano EO, Ludlow JB, Ørstavik D, Tyndall D, Trope M. Comparison between PAI and quantitative digital radiographic assessment of apical healing after endodontic treatment. Oral Surg Oral Med Oral Pathol Oral Radiol Endod. 2001;92:108-15.

5. Flint DJ, Paunovich E, Moore WS, Wofford DT, Hermesch CB. A diagnostic comparison of panoramic and intraoral radiographs. Oral Surg Oral Med Oral Pathol Oral Radiol Endod. 1998;85:731-5.

6. Kirkevang LL, Ørstavik D, Hörsted-Bindslev P, Wenzel A. Periapical status and quality of root fillings and coronal restorations in a Danish population. Int Endod J. 2000;33:509-15.

7. Kirkevang LL, Hörsted-Bindslev P, Ørstavik D, Wenzel A. Frequency and distribution of endodontically treated teeth and apical periodontitis in an urban Danish population. Int Endod J. 2001;34:198205.

8. Jiménez-Pinzón A, Segura-Egea JJ, Poyato-Ferrera M, VelascoOrtega E, Ríos-Santos JV. Prevalence of apical periodontitis and frequency of root-filled teeth in an adult Spanish population. Int Endod J. 2004;37:167-73.

9. Segura-Egea JJ, Jiménez-Pinzón A, Poyato-Ferrera M, VelascoOrtega E, Ríos-Santos JV. Periapical status and quality of root fi- llings and coronal restorations in an adult Spanish population. Int Endod J. 2004;37:525-30.

10. Segura-Egea JJ, Jiménez-Pinzón A, Ríos-Santos JV, VelascoOrtega E, Cisneros-Cabello R, Poyato-Ferrera M. High prevalence of apical periodontitis amongst type 2 diabetic patients. Int Endod J. 2005;38:564-9.

11. Segura-Egea JJ, Jiménez-Pinzón A, Ríos-Santos JV, Velasco-Ortega E, Cisneros-Cabello R, Poyato-Ferrera MM. High prevalence of apical periodontitis amongst smokers in a sample of Spanish adults. Int Endod J. 2008;41:310-6.

12. Pecoraro M, Azadivatan-le N, Janal M, Khocht A. Comparison of observer reliability in assessing alveolar bone height on direct digital and conventional radiographs. Dentomaxillofac Radiol. 2005;34:279-84.

13. Li G, Engström PE, Nasström K, Lü ZY, Sanderink G, Welander U. Marginal bone levels measured in film and digital radiographs corrected for attenuation and visual response: an in vivo study. Dentomaxillofac Radiol. 2007;36:7-11.

14. Guerrant GH, Moore WS, Murchison DF. Diagnostic utility of thermal printed panographs compared with corresponding computer monitor images. Gen Dent. 2001;49:190-6.

15. Ridao-Sacie C, Segura-Egea JJ, Fernández-Palacín A, BullónFernández P, Ríos-Santos JV. Radiological assessment of periapical status using the periapical index: comparison of periapical radiography and digital panoramic radiography. Int Endod J. 2007;40:43340.

16. Chugal NM, Clive JM, Spångberg LS. A prognostic model for assessment of the outcome of endodontic treatment: Effect of biologic and diagnostic variables. Oral Surg Oral Med Oral Pathol Oral Radiol Endod. 2001;91:342-52.

17. Orstavik D, Kerekes K, Eriksen HM. The periapical index: a scoring system for radiographic assessment of apical periodontitis. Endod Dent Traumatol. 1986;2:20-34.

18. Ríos Santos JV, Martín García P, Segura Egea JJ, Fernández-Palacín A, Bullón Fernández P. Audit of dental reports (II): first PhaseII study in a Spanish Faculty of Dentistry. Med Oral Patol Oral Cir Bucal. 2008;13:E529-35.

19. Russell M, Pitts NB. Radiovisiographic diagnosis of dental caries: initial comparison of basic mode videoprints with bitewing radiography. Caries Res. 1993;27:65-70.

20. Forner Navarro L, Llena Puy MC, García Godoy F. Diagnostic performance of radiovisiography in combination with a diagnosis assisting program versus conventional radiography and radiovisiography in basic mode and with magnification. Med Oral Patol Oral Cir Bucal. 2008;13:E261-5. 